\title{
China pushes to rule the waves
}

\section{Launch of huge Kexue research vessel could put country at forefront of ocean science.}

\section{BY JANE QIU IN BEIJING}

$\mathrm{T}$ he most sophisticated ship yet to join China's research fleet was launched last week, marking the latest step in the country's push to boost marine science.

Dubbed Kexue (which means 'science'), the 100-metre-long vessel dwarfs research ships operated by some other oceanography powerhouses, such as the United States. It "will be one of China's key research vessels in the next couple of decades", said Ding Zhongli, vice-president of the Chinese Academy of Sciences (CAS), at the launch ceremony on 30 November. "It is a state-of-the-art moving laboratory for fundamental research and technological development in marine science, especially deep-sea research."

Kexue, which cost about 550 million renminbi (US\$86 million), will be able to carry 80 people at a top speed of 15 knots on voyages of 28,000 kilometres, lasting up to 60 days. It is modelled on the United Kingdom's RRS James Cook and Norway's G.O. Sars, says Sun Song, director of the CAS Institute of Oceanology in Qingdao, Shandong province, which is in charge of Kexue's design and operation. "It is on a par with these top research vessels," he says.

Most ocean-going research vessels in China have been designed to explore for mineral or fuel resources, and although CAS and some universities have more than half a dozen vessels fitted out for scientific studies, few have the capacity to explore much further than China's coastal waters. "The lab space on those ships is very limited and facilities are not up to scratch," says Zhao Meixun, a marine ecologist at the Ocean University of China (OUC) in Qingdao. For example, Dongfanghong 2, an OUC research vessel, lacks the relevant sampling and measurement tool to study sea water's iron content - a vital nutrient for algae that absorb carbon dioxide. It also lacks equipment for detecting trace elements, or carrying out complex biological studies.

With 360 square metres of lab space, Kexue can accommodate a wide range of oceanographic studies, including measurements of ocean and atmospheric circulation, water and sediment sampling and on-board analyses, deep-sea exploration, acoustic studies and

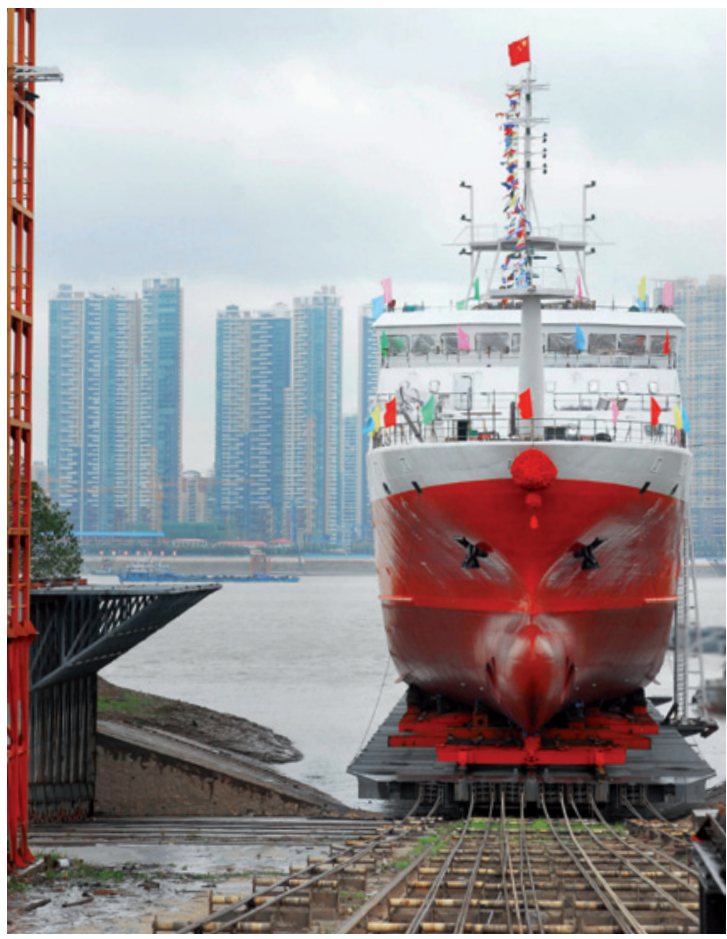

The Kexue research vessel was launched in Wuhan, China.

ocean-floor seismic experiments. It can also launch manned submersibles, such as the Jiaolong ('Sea dragon') craft, which descended to a depth of 5,000 metres in July.

"Kexue is an impressive ship with a lot of cool features," says Shangping Xie, a climatologist and oceanographer at the University of Hawaii in Honolulu. Its propellers, driven by electric motors, are housed inside pods that can be rotated in any horizontal direction, making the ship much more manoeuvrable than if it had a fixed propeller and rudder system, says Sun. The electric motors, together with noise- and vibration-reduction measures, make the ship particularly quiet ideal for marine-biology research. Kexue is the first research vessel in the world to boast these sophisticated propulsion pods, which together with positioning and motionreduction systems will allow it to maintain a fixed position in high winds and rough seas, says Sun.

Yet the ship could prove too costly for some researchers. Unlike countries, such as Japan and the United States, that bear the costs of scientists' ship time, China will ask scientists to pay a substantial portion of the costs of operating Kexue out of their own grants, says Xie. Weijun Cai, an oceanographer at the University of Georgia in Athens, says that Kexue should be complemented with more small- and medium-sized ships that allow small teams of scientists to carry out focused research on a lower budget. "This is particularly important for the majority of young and less wellfunded researchers," he says.

Other researchers say that to realize Kexue's full potential, there should be more sharing of data and equipment between marine scientists, and better technical training of on-board staff to ensure that data sets from different missions are comparable.

On Kexue's maiden voyage to the western Pacific Ocean next summer, scientists on board will study marine biodiversity, the deep-sea environment and the ocean's effect on climate in China. Researchers around the world are welcome to apply for ship time, says Sun. "Kexue will be a platform for joint marine research and observation with our foreign colleagues in the coming decades." -

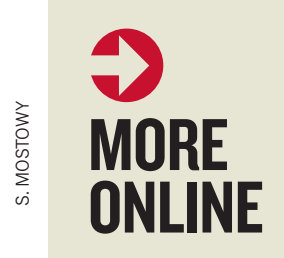

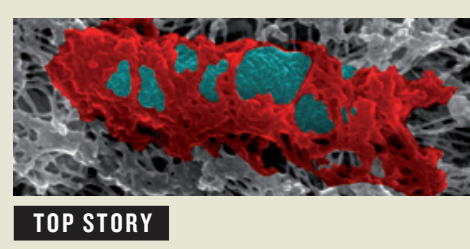

Septin proteins take bacterial prisoners go.nature.com/ri7s41

\section{MORE NEWS}

- Entangled diamonds vibrate together go.nature.com/rgfuf3

- Independent study affirms threequarters of climate change is manmade go.nature.com/lhjft3

- Voyagers detect birth pains of stars go.nature.com/bbrxw2

\section{VIDEO}

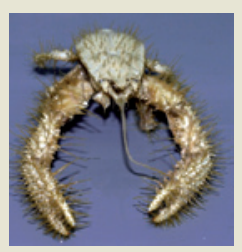

Yeti crabs living near methane seeps cultivate gardens of bacteria on their claws for food go.nature.com/ardltw 